\title{
An active school model to promote physical activity in elementary schools: Action schools! BC
}

\author{
P-J Naylor, ${ }^{1}$ H M Macdonald, ${ }^{2}$ D E R Warburton, ${ }^{3}$ K E Reed ${ }^{3}$ H A McKay ${ }^{2,4,5}$
}

${ }^{1}$ School of Exercise Science, Physical and Health Education, University of Victoria, Victoria, British Columbia, Canada;

${ }^{2}$ Department of Orthopaedics, University of British Columbia, Vancouver, British Columbia, Canada; ${ }^{3}$ School of Human Kinetics, University of British Columbia, Vancouver, British Columbia, Canada; ${ }^{4}$ Department of Family Practice, University of British Columbia, Vancouver British Columbia, Canada; ${ }^{5}$ Vancouver Coastal Health Research Institute, Vancouver, British Columbia, Canada

Correspondence to:

Dr Heather McKay, Centre for Hip Health, Vancouver Coastal Health Research Institute, 3022647 Willow Street, Vancouver, BC, Canada V5Z 3P1;

heather.mckay@ubc.ca

Accepted 7 January 2008

Published Online First

13 February 2008

\begin{abstract}
Objective: To assess the impact of an active school model on children's physical activity (PA).

Design: 16-month cluster randomised controlled trial.

Setting: 10 elementary schools in Greater Vancouver, BC.

Participants: 515 children aged 9-11 years.

Intervention: Action Schools! BC (AS! BC) is an active school model that provided schools with training and resources to increase children's PA. Schools implemented AS! BC with support from either external liaisons (liaison schools, LS; four schools) or internal champions (champion schools, CS; three schools). Outcomes were compared with usual practice (UP) schools (three schools).
\end{abstract}

Main outcome measurements: PA was measured four times during the study using pedometers (step count, steps/day).

Results: Boys in the LS group took 1175 more steps per day, on average, than boys in the UP group (95\% Cl: 97 to 2253). Boys in the CS group also tended to have a higher step count than boys in the UP group (+804 steps/day; 95\% Cl: -341 to 1949). There was no difference in girls' step counts across groups.

Conclusions: The positive effect of the AS! BC model on boys' PA is important in light of the current global trend of decreased PA.

Comprehensive whole school approaches to child health may represent a key strategy to address childhood obesity and other health issues. ${ }^{1-3}$ These models typically target multiple health issues based on local needs; incorporate a variety of strategies across settings; emphasise partnerships between school, family and community; and advocate for political and financial support from decisionmakers. ${ }^{45}$ Comprehensive, whole school approaches have also targeted single health issues such as healthy eating, ${ }^{2}$ and physical activity (PA) researchers ${ }^{3}$ have characterised this approach as an active school model.

Evidence to support the effectiveness of active school models is emerging, ${ }^{3}$ although most schoolbased studies have been conducted in middleschool or high-school settings. ${ }^{4-7}$ The few elementary school studies that used PA interventions largely focused on a single setting within the school environment, including: (1) modified physical education (PE) classes (for example, CATCH, SPARK) ${ }^{18}$ or the classroom curriculum (for example, Know Your Body, Eat Well and Keep Moving) ${ }^{9}{ }^{10}$; (2) additional PA opportunities (for example, Take 10, PLAY and Energizers) ${ }^{4511}$; or (3) modified playground environments. ${ }^{12}$

We designed an active school model for elementary schools in British Columbia (BC), Canada-
Action Schools! BC (AS! BC). ${ }^{13} 14$ The overall aims of the AS! BC model were to promote childhood PA and positively affect selected chronic disease risk factors ${ }^{15}$ using an active school approach. The focus of this paper was to determine the effect of the AS! BC model on children's PA levels. As the AS! BC trial was conducted to inform investment in a provincial roll-out of a school-based PA model, we also evaluated the model using two delivery approaches (external or internal facilitation) with different cost implications. We hypothesised that at the end of the study boys and girls attending schools randomly assigned to participate in AS! BC (either delivery approach) would be more physically active than children attending usual practice schools.

\section{METHODS \\ Design}

We undertook a large cluster randomised controlled trial to evaluate the effects of AS! BC on PA and selected chronic disease risk factors. Details of the study design and primary and secondary analyses are reported elsewhere. ${ }^{13} 1516$ In the present paper we undertook a post hoc analysis to determine the effect of AS! BC on children's PA levels. Physical activity was not a pre-specified end point for the trial and thus we did not perform a priori sample size or power calculations related to PA outcomes.

Schools were the unit of randomisation in order to prevent contamination that would occur if intervention and control children attended the same school. We conducted baseline measurements between February and March 2003 (fig 1). Intervention schools began implementing AS! BC in April 2003 and continued through May 2004 (with the exception of the summer holiday: July to August 2003). Therefore, although the trial spanned 16 months, the AS! BC intervention was implemented over an 11-month period. We conducted follow-up measurements between April and June 2004. The clinical ethics review board at the University of British Columbia approved this project.

\section{Participants}

We recruited schools from two school districts in British Columbia, Canada (Vancouver, Richmond) by presenting at district principals' meetings. Twenty elementary schools volunteered to participate. We excluded schools if they (1) were already undertaking a PA initiative, or (2) experienced high student mobility $50 \%$ of the student population per year). Based on results from the 2002 BC Ministry of Education Satisfaction 
Figure 1 Timeline of the Action Schools! BC intervention and measurement sessions. Pedometer data were collected at T2, T3, T4 and T5.

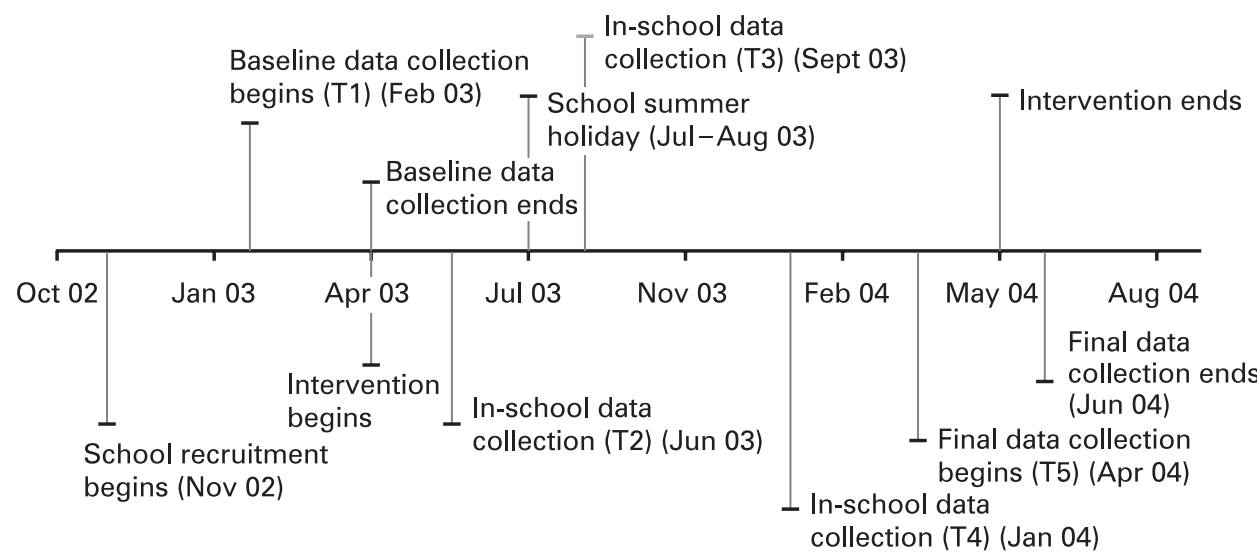

$\mathrm{T} 1=$ Questionnaire only, $\mathrm{T} 2-\mathrm{T} 5=$ Pedometers
Survey, ${ }^{17}$ eight schools were already undertaking a PA initiative and one school was deemed high mobility, thus, we invited 11 schools to participate. One principal withdrew his school (before randomisation) after determining that his school might be randomly assigned to the control group. Thus, 10 schools (three Richmond schools, seven Vancouver schools) participated in this study.

Once consent was obtained, we stratified schools by size ( $<300$ or $>300$ students to account for operational differences) and geographic location (to account for ethnic distribution). We extracted school size from district reports published by the $\mathrm{BC}$ Ministry of Education. ${ }^{18}$ All schools were then remotely randomised to one of three conditions: (1) liaison schools (LS) were provided with an external facilitator with whom teachers had weekly contact, training and all resources requested to implement AS! BC; (2) champion schools (CS) had a champion (facilitator) designated from within the school, were provided similar training to LS and basic resources needed to implement the model; (3) usual practice (UP) schools received no active intervention. To inform investment in a province-wide roll-out of the AS! BC model, we evaluated these two delivery approaches (liaison and champion) as they were associated with different cost implications.

Forty-two grades 4 and 5 teachers (98\%) consented to participate in Spring 2003 and 50 grades 5 and 6 teachers $(100 \%)$ consented in Fall 2003 (23 taught grade 5 across both years). Of 1084 eligible children, 515 (48\%) received parental consent to participate in the AS! BC evaluation. All grades 4 and 5 children enrolled in intervention schools participated in AS! BC activities, regardless of whether parents provided consent for their children to be evaluated. We excluded children from the present analysis if they had medical conditions that prevented participation in regular PA.

\section{Main outcome measurements}

We obtained the socioeconomic profile of each school district from district reports ${ }^{18}$; it was measured as the dollar amount that marked the mid-point of a distribution of families, with income ranked by size. We did not collect individual level data on socioeconomic status. We determined age and ethnicity of children who provided consent from a health history questionnaire completed by parent(s)/guardian(s) at baseline. Ethnicity was based on parents' and grandparents' place of birth. Our group has used this method of classification in previous school-based studies. ${ }^{19} 20$ We used Canadian census data for BC and Canada as a comparison measure. ${ }^{21}$

Our outcome variable for the present analysis was PA, which we assessed objectively using pedometers. We asked all children to wear a New Lifestyles Digiwalker SW-200 pedometer four times during the study period, with the first pedometer data collected approximately 6 weeks after the start of the intervention (fig 1). A research assistant instructed the children to wear the pedometer at the waist and in line with the thigh all day for four consecutive days. At the end of day 4, the research assistant collected the pedometers and recorded the total number of days the pedometer was worn and the number of steps taken. We used the average number of daily steps (step counts) across the four measurement sessions in our analysis to account for possible differences in physical activity across seasons. As not all children wore the pedometer for the full four days at each measurement period, we included data for those children who wore the pedometer for at least two sessions and two of the four measurement days per session. Pedometers provide a valid measure of children's $\mathrm{PA}^{22}{ }^{23}$ and a similar protocol has been used in previous studies. ${ }^{24} 25$

At baseline (T1), a trained research assistant administered the Physical Activity Questionnaire for Older Children (PAQ-C). This instrument is valid for use with this age group. ${ }^{26}{ }^{27} \mathrm{We}$ calculated PA score as an average of the nine PAQ-C items in a continuous range between 1 (low active) and 5 (high active).

\section{Intervention}

The AS! BC model, described in detail elsewhere, ${ }^{13}$ is consistent with the concept of an active school. ${ }^{32}$ The model emphasised an integrated whole school approach and extended beyond PE, to promote PA. The model was participatory, incorporating planning based upon local needs and specifically targeted six action zones: school environment, physical education, family and community, classroom action, school spirit and extracurricular. Each school convened an "action team" comprising teachers and principals. The AS! BC support team comprised two trained teachers, one PE teacher and one generalist teacher, who facilitated the design of a PA programme by school action teams. This programme was customised based on the perceived needs of the school and included activities across all six action zones with the aim of providing children with 150 minutes of PA per week. The only prescriptive component was within the classroom action zone; we asked teachers at intervention schools to provide students with 15 minutes of additional PA 
Table 1 Baseline age, distribution of ethnicities and baseline physical activity score (PA score) for boys and girls in the liaison (LS) and champion (CS) intervention groups and the usual practice (UP) group

\begin{tabular}{|c|c|c|c|c|c|c|}
\hline & \multicolumn{3}{|l|}{ Boys } & \multicolumn{3}{|l|}{ Girls } \\
\hline & LS & CS & UP & LS & CS & UP \\
\hline Number & 91 & 68 & 66 & 74 & 78 & 67 \\
\hline Age (years) & $10.2(0.6)$ & $10.1(0.6)$ & $10.3(0.6)$ & $10.3(0.6)$ & $10.1(0.6)$ & $10.3(0.5)$ \\
\hline No of Asian/white/other* & $37 / 43 / 11$ & $52 / 12 / 4$ & $32 / 22 / 12$ & $39 / 27 / 8$ & $46 / 20 / 12$ & $33 / 27 / 7$ \\
\hline PA score (1-5) & $2.5(0.1)$ & $2.7(0.1) \dagger$ & $2.6(0.1)$ & $2.4(0.1)$ & $2.5(0.05)$ & $2.6(0.1)$ \\
\hline
\end{tabular}

Values are mean (SD) unless otherwise indicated.

SD, standard deviation.

${ }^{*}$ Asian includes East, South-east and South Asian ethnicities, white includes North Americans of European descent and other includes children of mixed ethnicity or of other ethnicities such as South and Central American and Oceania.

$+\mathrm{CS}>\mathrm{LS}, \mathrm{p}<0.05$.

HS $<$ CS and UP, $\mathrm{p}<0.05$.

per school day or 75 minutes of additional PA per week in addition to two 40-minute PE classes per week. Within the classroom action zone teachers "snacked on PA" throughout the day and selected a number of activities including "Bounce at the bell,",15 20 video dance clips, playground circuits, exercise bands and stretching.

\section{Statistical analysis}

As we had multiple chronic disease outcomes in the trial, we determined sample size using our most conservative measure of change, bone strength. ${ }^{15}$ Based on $80 \%$ power, a type I error rate of $5 \%$ (two-sided) and a standard deviation of $5 \%$, a sample of 60 children was required. To allow for within-sex and betweenmaturity group comparisons and a 10\% attrition rate we required 264 children (across the 10 schools). However, to be inclusive we invited all children in grades 4 and 5 in each of the 10 schools to participate and, of these, $48 \%$ provided parental consent.

Trials that randomise clusters rather than individuals need to account for the intracluster correlation among individuals from the same cluster. ${ }^{29}$ Generalised estimating equations (GEE) and multi-level linear models, sometimes called hierarchical linear models or linear mixed models, are two commonly used strategies. In studies with a small number of clusters, as in the present study, the GEE has been shown to underestimate the standard error and thus, multi-level models are recommended..$^{30}$ Thus, to account for clustering within our analysis we performed multi-level modelling using xtmixed in Stata (Version 9.1; StataCorp, TX, USA). We designated group assignment as the fixed effect and school as the random effect. A random effect for a given school is constant and shared by all individuals within that school. The inclusion of this random effect accounts for clustering of students within schools.

Owing to known differences in physical activity between boys and girls in this age group. ${ }^{31}{ }^{32}$ we created separate multilevel models for boys and girls. We included baseline PA score as a covariate to account for any differences in PA across groups at study entry, which we assessed using univariate analysis of variance (ANOVA). We used standard residual plots to assess normality, linearity and homoscedacity. We calculated the intracluster correlation coefficient (ICC) as ICC $=\mathrm{s}_{\mathrm{c}}{ }^{2} /\left(\mathrm{s}_{\mathrm{c}}{ }^{2}+\mathrm{s}_{\mathrm{w}}{ }^{2}\right)$ where $\mathrm{s}_{\mathrm{c}}{ }^{2}$ equals the variance between clusters (schools) and $\mathrm{s}_{\mathrm{w}}{ }^{2}$ equals the variance within clusters. ${ }^{33}$

\section{RESULTS}

During the study, 69 (13\%) children were lost to follow-up and two children were excluded for medical reasons that prevented participation in regular PA. Thus, the present analysis included 444 children: 165 LS, 146 CS and 133 UP. The two school districts represented wide socioeconomic strata. The average family incomes in the Richmond and Vancouver districts ( $\$ 52524$ (£26 090; €34 216) and $\$ 51780$, respectively), were below both provincial and national averages ( $\$ 54840$ and $\$ 55016$, respectively). ${ }^{18}$ More than one quarter of families in both regions ( $26 \%$ and $27 \%$ ) had incomes below $\$ 30000$ per year. ${ }^{18}$

At baseline, children were $10.2(0.6)$ years of age (table 1). Children were 46\% East and South-East Asian, 24\% North Americans of European descent, 10\% South Asian, 13\% mixed and $8 \%$ other (including South and Central American, European, Oceania, North American Aboriginal, West Asian, Caribbean and Arab). This is representative of the Greater Vancouver area, with $37 \%$ of Vancouver residents and $59 \%$ of

Table 2 Average values across four measurement periods for pedometer step counts (steps/day) for liaison (LS), champion (CS) and usual practice (UP) children

\begin{tabular}{|c|c|c|c|c|}
\hline & \multicolumn{2}{|l|}{ Boys* } & \multicolumn{2}{|l|}{ Girls $\dagger$} \\
\hline & Mean step counts $(95 \% \mathrm{CI})$ & & Mean step counts $(95 \% \mathrm{CI})$ & \\
\hline$\overline{\mathrm{LS}}$ & $10982(10299$ to 11664$)$ & & 9667 (8764 to 10567$)$ & \\
\hline CS & 10569 (9776 to 11362 ) & & 9416 (8457 to 10375$)$ & \\
\hline \multirow[t]{2}{*}{ UP } & 9755 (8898 to 10611$)$ & & 8857 (7830 to 9883$)$ & \\
\hline & Mean difference (95\% CI) & p Value & Mean difference (95\% CI) & p Value \\
\hline LS vs CS & $371(-661$ to 1403$)$ & 0.48 & $190(-1136$ to 1516$)$ & 0.78 \\
\hline LS vs UP & 1175 (97 to 2253 ) & 0.03 & $730(-648$ to 2108$)$ & 0.30 \\
\hline CS vs UP & $804(-341$ to 1949$)$ & 0.17 & $540(-874$ to 1954$)$ & 0.45 \\
\hline
\end{tabular}

The adjusted mean differences between groups for step counts, determined with a mixed linear model, are also presented.

$\mathrm{Cl}$, confidence interval.

*75 LS, 63 CS, 49 UP.

$\uparrow 65$ LS, 72 CS, 54 UP. 
Richmond residents reporting being a member of a visible minority and $35 \%$ of Richmond residents and $25 \%$ of Vancouver residents reporting Chinese (Mandarin, Cantonese and Hakka) as their first language. ${ }^{21}$

\section{Physical activity}

We present baseline values for PA score in table 1. Boys in the CS group had a significantly higher baseline PA score than LS boys. There was no difference between UP and LS boys or between UP and CS boys. Girls in the LS group had a significantly lower PA score than girls in both the CS and UP groups.

We report adjusted means and mean differences between groups for step counts (average across four measurement periods) in table 2. Pedometer data were available for 378 (85\%) children. Boys in the LS group took 1175 more steps/day, on average, than boys in the UP group. Boys in the CS group also tended to take more steps per day than boys in the UP group, but the difference was not statistically significant. Girls' step counts were not significantly different across groups. The ICC for boys' step counts was 0.03 (95\% CI: 0.001 to 0.3 ) and for girls' step counts it was 0.11 (95\% CI: 0.03 to 0.24 ).

\section{DISCUSSION}

The Action Schools! BC model extends previous PA interventions by introducing a flexible active school model to provide significantly more opportunities for children to be physically active throughout the school day. We demonstrated that despite competing curricular demands, generalist elementary school teachers successfully incorporated the model into the regular school day. ${ }^{13}$ As a result, AS! BC had a modest positive but significant impact on PA levels of elementary schoolboys. Given the trend for children to decrease their activity levels with advancing age $e^{34}$ and the recent evidence regarding nonexercise activity thermogenesis (NEAT) ${ }^{36}{ }^{37}$ the accumulation of small caloric expenditures throughout the day may be important. These findings are meaningful to public health efforts that aim to counter escalating levels of childhood obesity. ${ }^{38}$

Our findings support other studies that used an environmentally oriented approach to promote PA. Both AS! BC and the Dutch JUMP-in mode ${ }^{35}$ incorporated PA breaks in the classroom, adopted an environmental approach to PA promotion and were developed in partnership with key stakeholders. Similar to AS! BC, results from JUMP-in indicated that the programme had a positive impact on children's PA. After one school year, JUMP-in appeared to prevent a decline in PA in grade 6 children in intervention schools. ${ }^{35}$ However, JUMP-in and AS! BC differed in a number of critical components. Importantly, JUMP-in was implemented by a PE specialist, implementation did not rely on school-based committees to plan and carry out activities throughout the school day and the model emphasised individually oriented strategies to address known psychosocial mediators of PA behaviour. Finally, the impact of JUMP-in on children's PA was assessed using questionnaires only.

A strength of the present study is that we used pedometers to objectively measure children's PA. Our findings support results from previous school-based studies that also used pedometers including Take 10! ${ }^{4}$ PLAY, ${ }^{5}$ and energisers. ${ }^{11}$ In the Take 10 ! study teachers provided 10 minutes of in-class PA in addition to PE and pedometers were used to monitor children's PA during Take 10 ! activities. ${ }^{4}$ During the one-week evaluation, grade 5 students took approximately 1022 steps during the 10 minutes of in-class activity. Similarly, teachers in the "energisers" study added 10 minutes of in-class activity daily over a 12 -week period and steps were reported for the whole school day and during the energisers activities. ${ }^{11}$ Children in energiser classes averaged 782 more steps/day than those in the control condition. ${ }^{11}$ Steps accumulated during the 10-minute energiser sessions ranged from 160 to 1223. In the present study, intervention children participated in approximately 10 minutes more classroom PA each day than children in control schools and the average step count difference between boys in the LS and UP groups was 1175 steps/day. Step counts were not statistically significantly different between boys in the CS and UP groups (although CS tended to be greater than UP) and this may reflect the fact that champion schools were provided with less hands-on external facilitation than liaison schools. ${ }^{13}$

Pangrazi et $a l^{5}$ also used pedometers to evaluate effects of the PLAY intervention on children's PA. Children in grades 4-6 were asked to undertake 30 minutes of PA per day, independent of their teacher. Self-monitoring and behaviour change strategies were also introduced. Although variability in daily steps was similar between PLAY and AS! BC (3000-4000 steps/day), children in the PLAY study averaged higher step counts compared with children in AS! BC (12 763 steps/day overall in the PLAY + PE condition; 11180 steps/day in controls)..$^{5}$ The mean difference between intervention and control groups was also greater in the PLAY trial (1583 steps) compared with AS! BC. The amount of planned PA between PLAY (30 minutes) and AS! BC (15 minutes) probably accounts for these differences. Seasonal effects and weather conditions may have also contributed to the lower average step counts for AS! BC children. PLAY was evaluated in the spring in Arizona whereas AS! BC was implemented across winter, spring and fall in Vancouver, Canada.

In light of the study design differences between AS! BC and PLAY, it appears that our results support those of Pangrazi et al. ${ }^{5}$ However, it is important to note that in the PLAY study, analysis by gender revealed a significant intervention effect for girls only. ${ }^{5}$ In contrast, our analysis by gender indicated significant group differences in step counts for boys only. We observed a general trend for girls participating in AS! BC to have higher step counts than girls in control schools. It is possible that the higher variability in girls' step counts may have prevented us from finding significant differences between groups. Further, it is possible that girls may have participated in more extracurricular activities that involved movement in the non-vertical plane and, thus, these activities would not be captured by pedometers.

We acknowledge that the present study has a number of limitations. Firstly, there are several methodological challenges associated with measurement of PA in children at this age. ${ }^{25} 39$ It seems important to replicate this trial with a more objective measure of PA such as accelerometers to provide insights as to where and when increased activity occurs and how this differs between boys and girls.

Secondly, although we randomised schools, participation by schools, teachers and children was voluntary. This may have introduced sampling bias. Approximately $48 \%$ of children consented to participate, but we do not know the characteristics of children who did not volunteer. Further, our recruitment rate was higher than some $e^{1}$ and lower than other ${ }^{8}$ schoolbased studies. The success of school-based interventions is highly dependent on recruitment at all levels: school districts, principals, teachers, parents and children. 


\section{What is already known on this topic}

To date, school-based physical activity interventions have largely been prescriptive and have focused on a single setting within the school environment (for example, physical education, playground or in class). Comprehensive, whole school approaches have been recommended because they engage stakeholders and recognise the importance of local context, which is critical to sustainability.

\section{What this study adds}

Our study shows that a well supported and flexible active school model, Action Schools! BC, that allows schools to customise the intervention based on their needs can positively benefit children's physical activity. These findings should be replicated in a variety of jurisdictions with long-term follow-up to determine if the promise of sustainability is fulfilled.

Thirdly, although we controlled for the clustered design within the analysis we were unable to power for this a priori. In addition, sample size for AS! BC was based on bone strength ${ }^{15}$ rather than PA outcomes and this, combined with the small number of clusters and variability in cluster size, may have limited our ability to demonstrate consistent intervention effects. ${ }^{40}$ Thus, the analyses in this paper should be considered exploratory and hypothesis-generating and we recommend that future studies attempt to overcome these limitations. That said, our findings are important in that we provide ICC values for a key PA outcome. These values are crucial when planning schoolbased trials to ensure sufficient statistical power. ${ }^{41}$

In summary, the AS! BC model was a novel, customised, participatory active school model that was feasible for generalist teachers to implement. ${ }^{13}$ We found with training and resources that teachers provided students with at least 10 additional minutes of PA per school day, in addition to PE. ${ }^{13}$ This increase translated into a positive influence on boys' PA levels in those schools where external support for teachers was available. This finding resonates in the current context of increasing prevalence of overweight and obesity among Canadian children ${ }^{42}$ and decreasing levels of PA in all children, which becomes more marked with increasing age. ${ }^{43}$ It may well be that an important role of school-based models is to maintain current levels of activity among children, so as to prevent further decline. There is a need for more studies that objectively assess children's PA to specify exercise intensity and the times within a child's day that are most influenced by school-based interventions.

Acknowledgements: We gratefully acknowledge the school administrators, teachers, parents and children from the Vancouver and Richmond school districts who participated in this study. We are also grateful for the assistance of the Action Schools! BC Support Team led by Bryna Kopelow and Jennifer Fenton of JWSporta. Dr Penny Brasher from the Centre for Clinical Epidemiology and Evaluation provided much appreciated statistical guidance.

Funding: We acknowledge funding support from the British Columbia Ministry of Health, 2010 Legacies Now, British Columbia Ministry of Tourism, Sport and the Arts and the Provincial Health Services Authority. HMM's postdoctoral studies are supported by the Canadian Institutes for Health Research (Interdisciplinary Capacity Enhancement grant). HAMcK is a Michael Smith Foundation for Health research senior scholar.

Competing interests: None.

\section{REFERENCES}

1. Luepker RV, Perry CL, McKinlay SM, et al. Outcomes of a field trial to improve children's dietary patterns and physical activity. The Child and Adolescent Trial for Cardiovascular Health. CATCH collaborative group. JAMA 1996;275:768-76.

2. Foerster SB, Gregson J, Beall DL, et al. The California children's 5 a day-power play! campaign: evaluation of a large scale social marketing initiative. Fam Community Health 1998;21:46-64.

3. Fox KR, Cooper A, McKenna J. The school and promotion of children's healthenhancing physical activity: perspectives from the United Kingdom. J Sch Health 2004;23:338-58.

4. Stewart JA, Dennison DA, Kohl HW, et al. Exercise level and energy expenditure in the TAKE 10! in-class physical activity program. J Sch Health 2004;74:397-400.

5. Pangrazi RP, Beighle A, Vehige $T$, et al. Impact of promoting lifestyle activity for youth (PLAY) on children's physical activity. J Sch Health 2003;73:317-21.

6. Simon C, Wagner A, DiVita C, et al. Intervention centred on adolescents' physical activity and sedentary behaviour (ICAPS): concept and 6-month results. Int J Obes Relat Metab Disord 2004;28(Suppl 3):S96-S103.

7. Felton G, Saunders RP, Ward DS, et al. Promoting physical activity in girls: a case study of one school's success. J Sch Health 2005;75:57-62.

8. Sallis JF, McKenzie TL, Alcaraz JE, et al. The effects of a 2-year physical education program (SPARK) on physical activity and fitness in elementary school students. Sports, Play and Active Recreation for Kids. Am J Public Health 1997:87:1328-34.

9. Bush PJ, Zuckerman AE, Theiss PK, et al. Cardiovascular risk factor prevention in black schoolchildren: two-year results of the "know your body" program. Am J Epidemiol 1989;129:466-82.

10. Gortmaker SL, Cheung LW, Peterson KE, et al. Impact of a school-based interdisciplinary intervention on diet and physical activity among urban primary school children: eat well and keep moving. Arch Pediatr Adolesc Med 1999;153:975-83.

11. Mahar MT, Murphy SK, Rowe DA, et al. Effects of a classroom-based program on physical activity and on-task behavior. Med Sci Sports Exerc 2006;38:2086-94.

12. Stratton G, Mullan E. The effect of multicolor playground markings on children's physical activity level during recess. Prev Med 2005;41:828-33.

13. Naylor PJ, Macdonald HM, Zebedee JA, et al. Lessons learned from Action Schools! BC—an 'active school' model to promote physical activity in elementary schools. J Sci Med Sport 2006;9:413-23.

14. Naylor PJ, Macdonald HM, Reed KE, et al. Action Schools! BC: a socioecological approach to modifying chronic disease risk factors in elementary school children. Prev Chronic Dis [serial online] 2006;3:A60. http://www.cdc.gov/pcd/issues/2006/apr/ 05 0090.htm (accessed 20 May 2006).

15. Macdonald HM, Kontulainen SA, Khan KM, et al. Is a school-based physical activity intervention effective for increasing tibial bone strength in boys and girls? J Bone Miner Res 2007;22:434-46.

16. Ahamed Y, Macdonald H, Reed K, et al. School-based physical activity does not compromise children's academic performance. Med Sci Sports Exerc 2007;39:371-6.

17. British Columbia Ministry of Education 2001-2002. 2001/02 Satisfaction Survey. Government of British Columbia, Victoria, BC.

18. British Columbia Ministry of Education. 2002 district reports. Government of British Columbia, Victoria, BC, 2002

19. MacKelvie KJ, Khan KM, Petit MA, et al. A school-based exercise intervention elicits substantial bone health benefits: a 2-year randomized controlled trial in girls. Pediatrics 2003;112:E447-52.

20. McKay HA, MacLean L, Petit M, et al. "Bounce at the bell": a novel program of short bouts of exercise improves proximal femur bone mass in early pubertal children. Br J Sports Med 2005;39:521-6.

21. Statistics Canada 2002. 2001 Community profiles, Ottawa.

22. Eston RG, Rowlands AV, Ingledew DK. Validity of heart rate, pedometry, and accelerometry for predicting the energy cost of children's activities. J App/ Physiol 1998;84:362-71.

23. Kilanowski CK, Consalvi AR, Epstein LH. Validation of an electronic pedometer for measurement of physical activity in children. Ped Exerc Sci 1999;11:63-8.

24. Janz KF, Witt J, Mahoney LT. The stability of children's physical activity as measured by accelerometry and self-report. Med Sci Sports Exerc 1995;27:1326-32.

25. Vincent SD, Pangrazi RP. Does reactivity exist in children when measuring activity levels with pedometers? Ped Exerc Sci 2002;14:55-63.

26. Crocker PR, Bailey DA, Faulkner RA, et al. Measuring general levels of physical activity: preliminary evidence for the physical activity questionnaire for older children. Med Sci Sports Exerc 1997;29:1344-9.

27. Kowalski KC, Crocker PR, Faulkner RA. Validation of the physical activity questionnaire for older children. Ped Exerc Sci 1997;9:174-86.

28. Cale L. Physical activity promotion in secondary schools. Eur PE Rev 2000;6:71-90

29. Bland JM, Kerry SM. Statistics notes. Trials randomised in clusters. BMJ 1997;315:600.

30. Feng Z, McLerran D, Grizzle J. A comparison of statistical methods for clustered data analysis with Gaussian error. Stat Med 1996;15:1793-806.

31. Sallis JF, Prochaska JJ, Taylor WC. A review of correlates of physical activity of children and adolescents. Med Sci Sports Exerc 2000;32:963-75.

32. Tudor-Locke C, Lee SM, Morgan CF, et al. Children's pedometer-determined physical activity during the segmented school day. Med Sci Sports Exerc 2006;38:1732-8.

33. Kerry SM, Bland JM. The intracluster correlation coefficient in cluster randomisation. BMJ 1998;316:1455. 
34. Van Mechelen W, Twisk JW, Post GB, et al. Physical activity of young people: the Amsterdam Longitudinal Growth and Health Study. Med Sci Sports Exerc 2000;32:1610-6.

35. Jurg ME, Kremers SP, Candel MJ, et al. A controlled trial of a school-based environmental intervention to improve physical activity in Dutch children: JUMP-in kids in motion. Health Promot Int 2006;21:320-30.

36. Levine JA. Non-exercise activity thermogenesis (NEAT). Nutr Rev 2004;62 (7 Pt 2):S82-97.

37. Levine JA, Lanningham-Foster LM, McCrady SK, et al. Interindividual variation in posture allocation: possible role in human obesity. Science 2005;307:584-6.

38. McKay HA, Macdonald $\mathrm{H}$, Reed KE, et al. Exercise interventions for health: time to focus on dimensions, delivery, and dollars. Br J Sports Med 2003;37:98-9.
39. Sallis JF. Self-report measures of children's physical activity. J Sch Health 1991;61:215-9.

40. Guittet L, Giraudeau B, Ravaud P. A priori postulated and real power in cluster randomized trials: mind the gap. BMC Med Res Methodol 2005:5:25-31.

41. Murray DM, Stevens J, Hannan PJ, et al. School-level intraclass correlation for physical activity in sixth grade girls. Med Sci Sports Exerc 2006;38:926-36.

42. Shields $\mathbf{M}$. Measured obesity: overweight Canadian children and adolescents. In: Nutrition: Findings from the Canadian Community Health Survey. Ottawa: Statistics Canada, 2005:1-34.

43. Brodersen NH, Steptoe A, Boniface DR, et al. Trends in physical activity and sedentary behaviour in adolescence: ethnic and socioeconomic differences. Br J Sports Med 2007;:41:140-4.

\section{Take advantage of BMJ Journals' remarkable catalogue of titles with Related Collections}

No busy professional has time to browse through all pertinent journals to find relevant articles, but with Related Collections you no longer have to. Follow the "Related Collections" link from any article and use the "Show Collections from other Journals" to expand your search across all BMJ Journals. Or simply follow the "Browse by topic" link on the home page. By setting up your own collections and receiving email alerts every time an article is added to your chosen area, you can build up your own significant body of knowledge. 